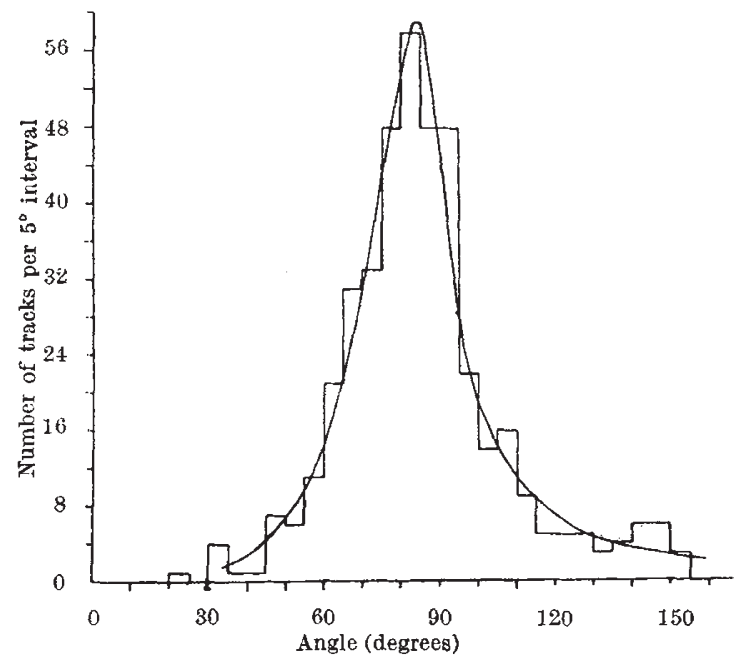

Fig. 2. Angle of emission of $\alpha$-particle relative to the light flssion fragment

Ordinate: Number of tracks per $5^{\circ}$ interval

Abscissa : Angle (degrees) measured from light flssion fragment.

expected from the theory ${ }^{16}$. Moreover, work with desensitized emulsions showed that these tracks were still present when the emulsion was no longer recording $\alpha$-particles, These experiments suggest that at least some of these short-range particles have a charge greater than 2 , and tracks of this class were found with ranges up to $5 \mathrm{~cm}$. of air $^{10}$, though the most probable value was observed to be $\sim 1 \mathrm{~cm}$. of air. After correction for random events caused by the chance superposition of fission tracks on the background of $\alpha$-particles and protons (from the reaction ${ }^{14} \mathrm{~N} n p^{14} \mathrm{C}$ ) which are present in the emulsions, a frequency of occurrence for these events can be obtained. Three-particle fission, in which the light fragment has a range less than $20 \mu$, was observed at the rate of 1 event per $85 \pm 10$ binary fissions. This frequency is in agreement with that found by Green and Livesey and Tsien et al., while the indication of fragments of $Z$ greater than 2 is supported by recent counter experiments of Dewan and Allen ${ }^{15}$.

(5) Although events comprised of three heavy fragments each of range greater than $5 \mu$ were observed in the emulsions, the geometry in all cases was compatible with their being formed by the collision of the fission fragments with silver and bromine nuclei in the heavy component of the emulsion. Moreover, the frequency of occurrence of these events was as predicted theoretically, assuming the interaction to be with the silver and bromine nuclei in the emulsion.

The experiments thus provide no evidence for fission into three approximately equal fragments as originally suggested by Present ${ }^{2}$, and, in this respect, confirm the counter experiment of Rosen and Hudson ${ }^{17}$. The event observed by Tsien et al. ${ }^{7}$ in which a particle of mass $\sim 32$ was emitted must therefore be regarded with suspicion, since if it were true ternary fission some fifty such events should have been observed in the present experiments.

A detailed account of these experiments is in preparation and will be published at a later date. Thanks are due to the ten microscope observers who, in the course of their training, worked on the problem with great diligence, and especially to Miss E. M. Chellingworth, who helped with the analysis. I am grateful to Sir John Cockcroft, director, Atomic Energy Research Establishment, Harwell, for permission to publish these results.

'Bohr and Whceler, Phys. Rev., 56, 426 (1939).

2 Present, Phys. Rev., 59, 466 (1941).

${ }^{3}$ See summary given by Allen and Dewan, Phys, Rev., 80, 181 (1950).

4 Wollan, Moak and Sawyer, Phys. Rev., 72, 447 (1947).

Demers, Phys. Rev., 70, 974 (1946).

-Green and Livesey, Phil. Trans., A, 241, 323 (1948).

T Tsien, Ho, Chastel and Vigneron, J. Phys., 8, 165, 200 (1947)

${ }^{2}$ Marshall, Phys. Rev., 75, 1339 (1949).

- Franzinetti and Payne, Nature, 161, 735 (1948). Titterton, Phil. Mag., 42, 113 (1951).

${ }^{10}$ Goward, Titterton and Wilkins, Nature, 164, 661 (1949).

${ }^{11}$ Titterton, Phys. Kev. (in the press).

12 Titterton, 1950 Harwell Conference Report, A.T.R.E., G/M.68, p. 79.

${ }^{13}$ Scott and Tittertort, Phil. Mag., 41, 918 (1950).

${ }^{14}$ Feather, Nature, 159, 607 (1947).

${ }_{15}$ Dewan and Allen, Phys. Rev., 76, 181 (A) (1949).

10 Bohr, Kgl. Danske Mat. Fysiske, 18, 8 (1948).

17 Rosen and Fudson, Phys. Rev., 78, 533 (1950).

\section{HIGHER EDUCATION IN BRITISH COLONIAL TERRITORIES}

$7 \mathrm{HE}$ report on measures for the economic development of under-developed countries, which has recently been issued by the United Nations Department of Economic Affairs, stressed the difficulties which the low level of technology in such countries present to their development. One major obstacle to the advance of technology in such countries is the absence of an educational and administrative structure through which the producers can learn technology. Even where leaders of such a country at various levels-politicians, teachers, engineers, business leaders, trade unionists, religious leaders, journalists -all desire economic progress, understand what is required, and are willing to pay the price, much will still depend on education. The preparation, as recommended in this report, of a programme of education and research for a period such as five years, indicating not only objectives and proposed expenditure, but also what is required for agricultural extension services, for industrial training, and for the training of scientific workers and administrators, will make considerable demands, in both its preparation and execution, on the services of trained minds in such countries.

It is in the light of such ideas and plans that the significance of the work of the Inter-University Council for Higher Education in the Colonies is best assessed to-day. The third report of the Council*, which covers developments since September 1949, is thus appropriately considered against the background provided by the general survey over roughly the same period provided by the current report "The Colonial Territories, 1950-51" $\dagger$, in which due weight is given to those political developments in self-government, for example, in the Gold Coast and Nigeria, which are making in themselves such demands on wise leadership by educated men and women. Those developments are summarized in Chapter 2 of the report, while the broad background of the educational situation is reviewed at the outset of Chapter 5, dealing with social services.

A feature of the report on "The Colonial Territories, 1950-51" is the evidence it supplies of the extent to * Colonial Office. Inter-University Council for Higher Education in the Colonies. Third Report, 1949-50. (Colonial No. 273.) Pp. 24. (London: H.M. Stationery Office, 1.95i.) $9 d$, net.

$\dagger$ The Colonial Territories, 1950-51. Pp. ix +184. (London: H.M. Stationery Office, 1951.) 4s. 6d. net. 
which the people of these territories are learning to increase their own revenues through a better use of their natural resources, to meet the many and varied professional and technical needs of their own countries -in medical and health work, in industry and com. merce as well as in social services of all kinds, including education - and to acquire the art of government through participation in their own political institutions. Much yet remains to be done. It is early yet to judge the success or otherwise of the constitutional developments in the Gold Coast, Nigeria and elsewhere, and both in health and in education there are serious shortages of staff which limit developments.

Nevertheless, the expansion of education, despite this and the other main limiting factor-finance-is again encouraging. In Malaya, the number of children at school increased by 50,000 during the year, and in Hong Kong, where seventy-three new schools were opened, by 30,000 . In Kenya a scheme has been approved for raising the standard of African education at an estimated annual cost of $£ 966,000$ and a capital outlay of $f 1 \frac{1}{2}$ million over the next five years; Nyasaland has completed a survey of schools as a basis for a detailed programme of development to be completed in 1954; and in Tanganyika the 'ten-year plan' has been revised to provide primary schooling for a much larger number of African children. All territories, however, are still hampered by a serious shortage of teachers, although local training facilities and their output are increasing and there is a large recruitment of teachers from the United Kingdom each year. In Nigeria, for example, there are now eighty-eight teacher-training centres, including twenty-two for women, and two rural education centres for training teachers in rural science. Education for girls is a sphere in which expansion is particularly important.

The exchanges between the United States and the Colonial territories under the Fulbright scheme, and the research work and surveys briefly summarized in this report make special demands on the trained men and women coming from the Colonial universities. Travel grants have already been approved under the scheme to enable thirteen candidates from Malaya, Singapore, Nigeria, Kenya and Uganda to visit the United States for study and research. Meanwhile, progress in starting the various Colonial research stations and institutes is frequently hindered by the shortage of qualified staff.

There are now three universities and five university colleges in the British Colonial territories and the Anglo-Egyptian Sudan, and of these the University of Malaya was founded in October 1949, Makere College achieved university college status in November 1949, and in February 1950 the University College of the West Indies installed its first chancellor. These eight institutions, according to the third report of the Inter-University Council, have a total of 3,056 full-time students, the University of Malaya having 791 students in the current session and the University of Hong-Kong 715, while in the 1949-50 session there were a further 4,014 Colonial students in the United Kingdom, of whom 1,745 were in universities and university colleges. The total has increased to about 4,500 in the current session, the proportion of university to non-university students being probably the same. Since in 1951 the minimum requirements for entrance to United Kingdom universities are being raised, the number of Colonial students qualified for admission will decrease, and the need for developing the Colonial universities and colleges and completing their building programmes will become the more urgent. The situation is now developing in fact in which a Colonial student will normally proceed overseas only for postgraduate and specialist courses or for courses not provided locally.

Excluding the Royal University of Malta, where much of the teaching is undertaken by part-time staff, there are now in the remaining institutions 130 professors or heads of departments, 24 readers or senior lecturers, 144 lecturers, 90 assistant lecturers and 69 part-time specialist staff (chiefly in the faculties of medicine) as well as 15 full-time staff in the extra-mural departments. The student/staff ratio varies considerably, from 8 at Hong-Kong to 28 at the University College of the Gold Coast; but the extent to which academic staffs of high qualifications have been recruited induces the Council to hope that it will invariably be possible to maintain a generous staff/student ratio, both because of the special teaching problems inherent in Colonial higher education and also because it is essential that the staff should have adequate time for research. It is also encouraging to note that the proportion of locally born staff is rising.

A feature of the latest report on Colonial research was the evidence of the close association in the Colonies between research and higher education, and during the year the Inter-University Council learned from the Colonial Research Council that the mutual advantages of such an association are fully recognized. The main volume of research at the Colonial university institutions, however, is the private work of the academic staff, and already this output from some five hundred specialists represents a substantial addition to the resources of science and scholarship. Its value should be enhanced by the Fullright scheme already mentioned, for under that scheme American professors, research workers and students are enabled to work in Colonial institutions; during 1950-51 there were twelve such academic guests at the Universities of Malaya and Hong Kong and the University Colleges of the West Indies, Gold Coast, Ibadan, and Makere.

While progress in building schemes is extending the laboratory facilities which make the Colonial universities and colleges attractive as centres for research, and on the financial side these institutions are receiving generous local support from governments as well as from private organizations and individuals, appreciable progress is also reported in the libraries of all these institutions-in their holdings, administration, staffing and services. Again, particularly at the Colleges in the West Indies, the Gold Coast and Ibadan, extra-mural departments have been well developed, while all five university colleges are in a special relationship with the University of London to assist them to establish their standards and to devise the curricula and syllabuses for the degrees which they will award when strong enough to assume independent university status. Under this scheme, moreover, the University has made a separate arrangement with each of the colleges to meet the problem of entrance requirements and matriculation arising from the introduction by the Home Universities in 1951 of new minimum requirements for admission. The Council also welcomes the establishment in October 1949 of the Advisory Committee on Colonial Colleges of Arts, Science and Technology, and has held joint meetings with this advisory committee to discuss engineering education. Three such colleges have been established, in Nigeria, the Gold 
Coast and Sierra Leone, and one of their most important functions will be to teach technical and commercial subjects up to professional level and to increase facilities for teacher training.

Technical education at the lower levels is, in fact, receiving increasing attention everywhere in the territories: in Uganda the main educational effort is towards schools of a less academic type; the junior technical schools in Malaya are filled to capacity, while a course in architecture has been added at the Technical College in Kuala Lumpur, and building for a new technical college is about to commence.

All these developments involve demands on the Colonial universities and university colleges and affect their work as well as the prospects for their students. But while the Inter-University Council has clearly been considering a wide range of problems as well as the factual developments recorded in this report, it scarcely touches on some fundamental issues concerning the position of university institutions in Colonial society. Satisfied that adequate academic standards of work have been attained and are likely to be maintained, the Council does indeed recognize that it is now becoming important to ensure that the most effective use is made of the services of students trained in such institutions, from the point of view of the students themselves and of their peoples. But it contents itself with expressing the hope that too high a proportion of the graduates will not be absorbed into government service, because of the importance of introducing some of this sure experience and trained ability into other sectors of society, such as journalism, commerce and industry.

The future of the Colonial universities does not depend solely on their ability to maintain high academic standards: it depends equally on their ability to provide the societies which they exist to serve with trained men and women who can meet the needs of these societies and fit happily into their way of life. If there is no place in such societies for the men and women coming from the new university institutions, no opportunity for the utilization of their technical or professional ability, and no adequate or satisfying cultural life, those institutions will themselves ultimately decay. The absorption of trained man- and woman-power into the Colonial life of to-day involves difficult and interesting problems, and the Inter-University Council could appropriately have used its annual report to discuss one or two such topies, particularly those bearing on the relationship between university education and secondary or primary education.

\section{CURRENT TRENDS IN SOCIAL PSYCHOLOGY}

$\Delta \mathrm{T}$ the recent Edinburgh meeting of the British A Association, Section J (Psychology) devoted each of its five mornings to current trends in psy. chology, and in one session, "Current Trends in Social Psychology", four papers were presented which had many interlocking features. The first, by Dr. H. J. Eysenck, described researches into social attitudes. He held that popular newspaper polls of public opinion, the Gallup and similar polls, though interesting, are of little scientific value. Newspaper polls ask broad, general questions, and do not take sufficient account of the political affiliations of people questioned. Investigation into attitudes towards different issues of present-day importance show a great tendency for certain attitudes to cluster together in a manner characteristic of Radicals and Conservatives.

Dr. Eysenck propounded a distinction between what he calls "tough-minded" and "tender-minded" persons. (It is perhaps unfortunate that this distinction, well known in psychology since the late Prof. William James first used these terms, has been accepted by psychologists as meaning something different, but not entirely different, from Dr. Eysenck's new use of the term.) He contrasted the moral approach of the tender-minded, who are idealistic, ethical, religious and to whom the individual is sacrosanct, and the tough-minded, who believe in the inferiority of coloured people, Jews and women, and in the 'inevitability' of war. The working-class person, he said, is on the average very much more tough-minded and conservative than the average middle-class person. He described recent investigations into the organization of attitudes, their relation to political-party membership, age, sex, education, social class, and personality, and also into the effect upon the structure of attitudes of differences in culture-pattern.

The second paper, on "Personality Tests as Research Tools", by Dr. Hilde T. Himmelweit, considered 'objective' tests that require the subject to perform some task under standard conditions, the response to which can be objectively measured. Examples of these tests are of motor co-ordination, speed and accuracy of response, suggestibility, persistence, levels of aspiration and expressive movement. Though the behaviour involved in these may throw light on deeper mental levels, such tests do not tap these levels as specifically as projection tests do, and yet the results of objective tests are unaffected by the psychologist's subjective interpretation of the responses.

The use of batteries of objective tests makes possible the investigation of entirely new problems. One concerns the relationship between normal, neurotic and psychotic states. Kretschmer has maintained that these conditions differ from each other only quantitatively, not qualitatively, and can be viewed as lying along the same continuum with schizophrenia and manic-depressive psychosis. Eysenck, using a wide range of objective personality tests, has found that, on most tests, the patterning or inter-correlations of the test result was sufficiently similar in the normal and psychotic groups to support strongly Kretschmer's hypothesis. Objective tests are also useful in studying the effect upon the personality of leucotomy. Azenath Petrie has given tests to patients before and at stated intervals after this operation. The results enabled her to describe the characteristics of the postleucotomy personality.

Objective tests will be used in a research, being carried out at the London School of Economics, into the differences in attitude to personality characteristics of young adolescents from different social classes. They will test the hypothesis proposed by Davis, of Chicago, that middle-class parents cherish higher aspirations for their children than workingclass parents, that the child tends to introject the parents' demands and to react by having higher aspirations and being anxious regarding their attainment. It is proposed to find the extent to which middle-class children, compared with children from 